\title{
Erratum to: $\quad$ Electronic Catalogue of Mesoroentgen Spectra
}

\section{R. Zinatulina ${ }^{1}$ *}

Received July 10, 2020; revised July 10, 2020; accepted July 10, 2020

DOI: $10.1134 / \mathrm{S} 1063778820050233$

Section Funding should read as follows:

The work was supported by Russian Foundation for Basic Research (grant no. 18-32-00383-Mol_a).

The original article can be found online at https://doi.org/10.1134/S1063778819030165

1) Joint Institute for Nuclear Research, Dubna, Moscow oblast, 141980 Russia.

*E-mail: d.zinatulina@gmail.com 